\title{
Teenage Pregnancy and Obstetric Outcome: A Comparative Study in Urban Nigeria.
}

\author{
Ikeanyi Eugene, Israel Jeremiah, Ekine Atombosoba \\ Department of Obstetrics and Gynecology, Niger Delta University, Wilberforce Island, P.M.B.071, Bayelsa State, \\ Nigeria, Nigeria.
}

Received: December 24, 2015 ; Accepted: February 2, 2016

Aims: Teenage pregnancy is a worldwide problem that poses social and health concerns in both industrialized and developing countries. This study therefore sought to evaluate the relevance of age at first pregnancy on obstetric performance.

Methods: This was a case control analytical observational study of teenage women as study group and older control subgroup aged 20-34 years that had their first childbirth between 2009 and 2013 at a mission Hospital in Benin City, South- South, Nigeria. Statistical analysis was with computer statistical soft ware with statistical significance set at $\mathrm{p}<.05$.

Results: The incidence of teenage nullipara in this study was $1.1 \%$. The study group were more likely to be unmarried $(\mathrm{OR}=9.6, \mathrm{P}<0.001)$, unemployed $(\mathrm{OR}=6.6, \mathrm{P}=0.001)$, attain below secondary level of education $(\mathrm{OR}=8.4, \mathrm{P}<0.001)$ and less likely to attain post secondary level of education $(\mathrm{OR}=0.05, \mathrm{P}<0.001)$, lack prenatal care $(\mathrm{OR}=2.0, \mathrm{P}=0.33)$, have vaginal delivery (OR: $5.7, \mathrm{P}=0.01)$, less caesarean section rate $(\mathrm{OR}=0.2, \mathrm{P}=0.01)$, weigh less at booking and last prenatal visits $(\mathrm{P}<0.001)$ respectively and neonates weighing less at birth $(\mathrm{t}=2.1, \mathrm{P}=0.04)$.

Conclusions: Teenage pregnancy was more a social than an obstetric problem. Adequate empowerment before reproductive role, discouragement of early marriage and or childbearing is hereby proffered.

Keywords: Comparative study, first pregnancy, teenage nullipara, urban Nigeria

\section{INTRODUCTION}

Teenage period is widely considered in and outside the obstetric world, an early, premature and not the optimal period for reproduction. Teenage pregnancy is pregnancy in a woman aged $10-19$ years. ${ }^{1}$ It is therefore expected to be associated with increased adverse maternal and perinatal outcomes. About a tenth of 130 million global annual births are by adolescent mothers and $90 \%$ of these are in the developing countries. ${ }^{2}$ Sub-Saharan Africa has the highest teenage pregnancy rate with the incidence of 143 per 1000 girls aged $15-19$ years. ${ }^{3}$ In Nigeria 23\% of women aged 15-19 years have begun childbearing while $18 \%$ have had a child and $5 \%$ were currently pregnant with their first child. ${ }^{4}$

The lower incidence in industrialized regions is due to high levels of awareness, availability and utilization of contraception. ${ }^{1}$ The observed regional difference is not due to variation in sexual behavior, biological

\section{CORRESPONDENCE}

Dr. Ikeanyi Eugene

Department of Obstetrics and Gynecology, Niger Delta

University, Wilberforce Island, P.M.B.071, Bayelsa State, Nigeria Nigeria.

E-mail: abuchikeanyi@yahoo.com

Telephone: +234-08033528344 or racial reasons. ${ }^{1}$ It occurs in every society but the incidence and the acceptability is influenced by existing cultural and religious practices. ${ }^{1}$ Disruptive early life is the key to most of teenage pregnancies. ${ }^{5}$ Psychosocial and economic support early in life therefore is expected to reduce the incidence of teenage pregnancy. There is significant relationship between teen's pregnancy and parental socioeconomic status ${ }^{6,7}$ and the media. ${ }^{7}$ Other influencing factors at individual level are marital status, educational level, age of sexual debut, and living location. ${ }^{8} \mathrm{~A}$ national survey in Nigeria noted that median age at first child birth increases with the level of education and socioeconomic status of the household and vice versa. ${ }^{4}$

Available scientific data suggest that pregnancy before the age 20 years is prone to adverse obstetric outcomes. International data have profusely shown complications of pregnancy and childbirth to be the leading cause of death among girls aged 15 to 19 years in poorer countries. ${ }^{2}$ Sub-Sahara Africa is home to 9 out of the 10 countries with the highest risk for early motherhood. ${ }^{2}$ Teenage pregnancy is 
globally considered a social problem with medical consequences. In industrialized regions of North America and West Europe it is majorly social problem because most of the pregnant teenagers are unmarried. ${ }^{1,3}$ On the contrary, in developing countries most of them tend to be married and their pregnancies planned and desired by the family and the society, however, the prevailing poor socioeconomic state and malnutrition in a poor healthcare system result in increased medical problems. ${ }^{1}$ Most of such pregnancies therefore indicate increased maternal and perinatal complications.

There were a lot of conflicting reports on most of these complications. While many data indicated increased maternal and perinatal complications 2,9 others recorded reduced incidence or no difference $\mathrm{e}^{10-12}$ in the adverse obstetric outcome relative to the older mothers. The teenagers are assumed more prone to cephalopelvic disproportion and obstructed labor with consequent increased caesarean births. ${ }^{1}$ This is due to their immature and developing bony pelvis and genital system though a study could not confirm this. ${ }^{1}$

The outcome of teenage pregnancy and child birth remains controversial in obstetric world despite the plethora of scholarly scientific literatures. This conflicting evidence stimulated the interest for this study. As a leading cause of mortality among the young girls and a serious social problem to the society, it was hoped that contribution of data to the pool of the evidence on teenage pregnancy will assist in designing and promoting adolescent health programs to reduce its incidence and prevent the complications.

\section{METHODS}

This was a comparative observational study of the women aged $\leq 19$ years at their first child birth as the study group and those aged 20-34 years as the control group. The study took place at St Philomena Catholic Hospital (SPCH) Benin City South-south, Nigeria between June 2009 and December 2013. Nulliparous women aged 35 years and above were excluded. Those who had multiple pregnancies were also excluded from the study to avoid confounding on preterm rate and the mean birth weight.

The study center is a long serving secondary tier mission health facility with fairly well equipped and staffed maternity and neonatal departments. The medical record unit was fairly satisfactory. It has about a thousand annual delivery rates. The facility has longstanding and adequate obstetric and pediatric services.

The case file number of each of the subjects was traced by the authors from the hospital labor ward register while the files were retrieved with the assistance of the staff of the medical records unit. Database was raised on their socio-demographic characteristics, prenatal, labor and delivery details, pregnancy outcomes and immediate postpartum. All the eligible subjects were recruited into the study.

The main outcome measures were maternal and perinatal complications. Maternal outcome variables were the rate of caesarean section(CS) ,other interventional delivery (induction of labor (IOL),augmentation of labor (AOL), premature rupture of fetal membranes (PROM) ,assisted vaginal delivery(AVD)), blood transfusion, human immunodeficiency virus (HIV) infection, pregnancy induced hypertension/preeclampsia, obstetric hemorrhage ( ante partum and postpartum hemorrhage), hysterectomy and maternal death.

Perinatal outcome measures were Apgar Score at 5 minutes, Low birth weight (LBW), intrauterine growth restriction (IUGR), preterm birth, prolonged pregnancy, macrosomia, stillbirth(SB), early neonatal death (ENND), perinatal mortality (PNM) (SB,ENND), special care baby unit (SCBU) admission.

For the purpose of this study in Nigeria the gestational age cut-off is taken at 28 completed weeks for viability. A pregnant nullipara (para 0 ) is currently pregnant irrespective of the gestational age and number of previous early pregnancy losses (abortions, ectopic pregnancies etc). Until she delivers after the age of fetal viability when her parity status will change to (para 1 or primipara) she remains a nullipara. A gestational period spans from conception of pregnancy to its termination, in this study childbirth. Teenage pregnancy is pregnancy in a girl $\leq 19$ years of age. A teenager can be of any parity; nullipara (para 0), primipara (para 1) or multipara ( > para 1). This study evaluated pregnancy and the outcomes in para 0 teenage mothers in relation to their older counterparts. Preterm birth was a birth before 37 completed weeks of gestation from the date of onset of the last normal menstrual period (LNMP) and if a gestational period is beyond 40 completed weeks it 
was taken as a prolonged pregnancy. Newborn weight less than 2500 grams at birth was considered low birth weight and 4000 grams or greater was macrosomia. Maternal blood pressure of $140 / 90 \mathrm{mmHg}$ or greater with or without significant proteinuria is diagnosed as gestational hypertension. Gynecological age was defined as the interval between the age in years at menarche and the age at first conception.

The study was approved by the hospital Ethics and Research Committee (REC). There was no involvement of patient identifiers in the data collection process therefore consent from the individual patients was not required.

Analysis was done with EPI-INFO Version 3.5.1 and INSTAT statistical software. Statistical tests were done with chi-square while Student's $t$ - test was used for the comparison of the means. Statistical significance was set at $\mathrm{p}$-value $<.05$.

\section{RESULTS}

A total of $1730 / 3976(43.5 \%)$ had their first delivery as nullipara at the center within the study period and 1632 were eligible after the exclusions and subsequent analyses were limited to them. The teenage nulliparous mothers were (42)1.1\% of all the deliveries and $2.4 \%$ of the nulliparae at the centre during this study. The mean age of the study group (teenagers) was $18.5 \pm 0.7$ years and modal age was 19 years in a range of 17-19years and the values for the control group were $26.9 \pm 3.2$ years and modal age was 27 years. The mean age difference of 8.4 years was statistically significant $(\mathrm{t}=16.8, \mathrm{P}<0.001)$

From Table 1, the study group were more likely to be unmarried (OR: 9.6, $\mathrm{P}=0.001$ ), unemployed (OR 6.6, $\mathrm{P}<0.001$ ), attain less than secondary level of education (OR: 8.4, $\mathrm{P}<0.001$ ), less likely to attain post secondary level of education (OR: 0.05, $\mathrm{P}<0.001)$ at the time of their first childbirth. The observed differences were statistically significant. They were twice more likely to be unbooked $(\mathrm{OR}=2.0$, $\mathrm{P}=0.33$ ). This was not statistically significant. The two arms were similar in mean height $(\mathrm{P}=0.31)$, yet the study group significantly weighed less than the control group at their first and last antenatal visits respectively. The mean weight difference at booking and last prenatal visits of $8.2 \mathrm{~kg}$ respectively were each statistically significant $(\mathrm{t}=3.9, \mathrm{P}<0.001, \mathrm{t}=3.8$ $\mathrm{P}<0.001)$

Table 1: Maternal Socio-demographic Characteristics by Age groups

\begin{tabular}{|c|c|c|c|c|c|c|}
\hline \multirow{2}{*}{$\begin{array}{l}\text { Variables } \\
\text { Marital status: }\end{array}$} & \multicolumn{2}{|c|}{ Age in years $(\mathrm{N}=1632)$} & \multirow{2}{*}{$\begin{array}{l}\text { OR } \\
91(97.5)\end{array}$} & \multirow[t]{2}{*}{$\mathrm{t}$} & \multirow[t]{2}{*}{$95 \% \mathrm{CI}$} & \multirow[t]{2}{*}{ P-value } \\
\hline & $\leq 19 n=41(2.5)$ & $20-34 n=15$ & & & & \\
\hline Married & $38(92.7)$ & 1578(99.2) & 0.1 & - & $0.03-0.38$ & $0.001 *$ \\
\hline Unmarried & $3(7.3)$ & $13(0.8)$ & 9.6 & - & $2.6-35.03$ & $0.001 *$ \\
\hline Unemployed & $32(78.0)$ & $558(35.1)$ & 6.6 & - & $3.12-13.90$ & $0.001^{*}$ \\
\hline Employed & $9(22.0)$ & 1033(64.9) & 0.2 & - & $0.07-0.32$ & \\
\hline \multicolumn{7}{|l|}{ Educational } \\
\hline \multicolumn{7}{|l|}{ Attainment: } \\
\hline$<$ Secondary & $6(14.6)$ & $32(2.0)$ & 8.4 & - & $3.28-21.26$ & $<0.001 *$ \\
\hline Secondary & $31(75.6)$ & $450(28.3)$ & 7.9 & - & $3.82-16.17$ & $<0.001^{*}$ \\
\hline$>$ Secondary & $4(9.7)$ & $1109(69.7)$ & 0.05 & - & $0.02-0.13$ & $<0.001^{*}$ \\
\hline Unbooked & $4(9.8)$ & $81(5.1)$ & 2.0 & - & $0.70-5.79$ & 0.33 \\
\hline Mean height $(\mathrm{cm})$ & $160.3 \pm 6.6$ & $161.7 \pm 8.0$ & - & 1.0 & - & 0.31 \\
\hline \multicolumn{7}{|l|}{ Mean weight (kg) } \\
\hline At booking & $61.6 \pm 9.6$ & $69.8 \pm 12.8$ & - & 3.9 & - & $0.001 *$ \\
\hline \multicolumn{7}{|l|}{ Mean weight (kg) } \\
\hline At last prenatal visit & $69.9 \pm 11.1$ & $78.1 \pm 12.8$ & - & 3.8 & - & $0.001 *$ \\
\hline
\end{tabular}

*Significant. All values in bracket are percentages

From Table 2, among those who had prenatal care at the center, the study group comparatively had increased risk of anemia at their first visit $(29.3 \%$ vs. $28.8 \%, \mathrm{OR}=1.02, \mathrm{P}=0.95)$. This was not statistically significant. Similarly, they were more prone to premature rupture of fetal membranes $(\mathrm{OR}=1.4$, $\mathrm{P}=0.74)$ and to suffer gestational hypertension (OR-
$1.5, \mathrm{P}=0.44)$.These were not statistically significant. The study group had less preterm labor and delivery ( $2.4 \%$ vs. $7.7 \%, \mathrm{OR}=0.30, \mathrm{P}=0.33)$ and were about $40 \%(26.8 \%$ vs. $40.0 \%, \mathrm{OR}=0.55, \mathrm{P}=0.12)$ less likely to have prolonged pregnancy. They were also at reduced risk of induction of labor $(12.5 \%$ vs. $22.6 \%$, $\mathrm{OR}=0.56, \mathrm{P}=0.31)$ and augmentation of labor $(17.5 \%$ 
vs. $26.5 \%, \mathrm{OR}=0.47, \mathrm{P}=0.10$ ). None of these was statistically significant. They had reduced risk of cephalopelvic disproportion (CPD)/obstructed labor ( $2.4 \%$ vs. $14.2 \%, \mathrm{OR}=0.15, \mathrm{P}=0.05)$. This was not statistically significant. Caesarean section rate was about $80 \%$ reduced among the study group $(\mathrm{OR}=0.17$, $95 \%$ CI: $0.04-0.72, \mathrm{P}=0.01)$. This was statistically significant. Compared with the control group, most ( $58.5 \%$ vs. $45.6 \%, \mathrm{OR}=1.68, \mathrm{P}=0.14$ ) of the study group required episiotomy yet they had more perineal tear $(14.6 \%$ vs. $12.0 \%, \mathrm{OR}=1.3, \mathrm{P}=0.79)$. However, this was not statistically significant. They were nonetheless, less prone to obstetric hemorrhage ( 0 vs. $4.0 \%$ ) and blood transfusion ( $0 \%$ vs. $1.3 \%$ ).

Table 2: Maternal Outcome Variables by Age groups

\begin{tabular}{|c|c|c|c|c|c|}
\hline \multirow{2}{*}{$\begin{array}{l}\text { Variables } \\
\text { Age group }\end{array}$} & \multicolumn{2}{|c|}{ Age in years $(\mathrm{N}=1632)$} & \multirow[t]{2}{*}{ OR } & \multirow[t]{2}{*}{$95 \% \mathrm{CI}$} & \multirow[t]{2}{*}{ P-value } \\
\hline & $\leq 19$ & $20-34$ & & & \\
\hline $\mathrm{N}(\%)$ & $41(2.5)$ & $1591(97.5)$ & & & \\
\hline \multicolumn{6}{|l|}{ ComplicationsOf pregnancy: } \\
\hline Anemia (booking) & $12(29.3)$ & $459(28.8)$ & 1.02 & $0.52-2.02$ & 0.95 \\
\hline HIV-seropositive & 0 & $49(3.1)$ & - & - & - \\
\hline $\begin{array}{l}\text { Antepartum } \\
\text { Hemorrhage }\end{array}$ & 0 & $23(1.4)$ & - & - & - \\
\hline PIH/Preeclampsia & $9(22.0)$ & $258(16.2)$ & 1.5 & $0.69-3.08$ & 0.44 \\
\hline Preterm labor/delivery & $1(2.4)$ & $123(7.7)$ & 0.30 & $0.4-2.2$ & 0.33 \\
\hline Prolonged pregnancy & $11(26.8)$ & $637(40.0)$ & 0.55 & $0.27-1.12$ & 0.12 \\
\hline Malpresentation & $1(2.4)$ & $48(3.0)$ & 0.80 & $0.11-5.97$ & 1.00 \\
\hline Premature rupture Of membranes & $4(9.8)$ & $114(7.2)$ & 1.4 & $0.49-4.00$ & 0.74 \\
\hline Type of labor: Spontaneous & $28(71.8)$ & $746(50.9)$ & 1.65 & $0.81-3.34$ & 0.22 \\
\hline Induced & $5(12.5)$ & $331(22.6)$ & 0.56 & $0.22-1.44$ & 0.31 \\
\hline Augmented & $7(17.5)$ & $389(26.5)$ & 0.47 & $0.21-1.10$ & 0.10 \\
\hline Mode of delivery: Spontaneous vaginalDelivery & $39(95.1)$ & $1229(77.2)$ & 5.74 & $1.38-23.91$ & $0.01 *$ \\
\hline Assisted Vaginal Delivery & 0 & $16(1.0)$ & - & - & - \\
\hline Caesarean section & $2(4.9)$ & $362(22.8)$ & 0.17 & $0.04-0.72$ & $0.01 *$ \\
\hline Postpartum hemorrhage & 0 & $41(2.6)$ & - & - & - \\
\hline Blood transfusion & 0 & $20(1.3)$ & - & - & - \\
\hline $\mathrm{CPD} / \mathrm{Obstructed} \mathrm{labor}$ & $1(2.4)$ & $226(14.2)$ & 0.15 & $0.02-1.10$ & $0.05^{*}$ \\
\hline Episiotomy & $24(58.5)$ & $726(45.6)$ & 1.68 & $0.89-3.16$ & 0.14 \\
\hline Perineal tear & $6(14.6)$ & 191(12.0) & 1.26 & $0.52-3.05$ & 0.79 \\
\hline
\end{tabular}

*Significant. All values in bracket are percentages. ${ }^{t}$ Cephalopelvic disproportion

From Table 3, the newborns of the study group were The neonates of the study group weighed significantly about half $(\mathrm{OR}=0.51, \mathrm{P}=0.8)$ less likely to have less $(\mathrm{t}=2.1, \mathrm{P}=0.04)$. This was corroborated by more Apgar score of less than 7 at 5 minute than those of the than twice increase in the risk of low birth weight control group. This was not statistically significant.

among the neonates of the study group $(\mathrm{OR}=2.2$, $\mathrm{P}=0.2)$.

Table 3: Perinatal Outcome Variables by Maternal Age groups $(\mathrm{N}=1632)$

\begin{tabular}{|lllllll|}
\hline Variables & \multicolumn{1}{l}{ Age in years $(\mathrm{N}=1632)$} & OR & t-test & 95\%CI & P-value \\
\hline Age group & $\leq 19$ & $20-34$ & - & - & - & - \\
$\mathrm{N}(\%)$ & 41 & 1591 & - & - & - & - \\
APGAR score $<7$ at 5min & $1(2.4)$ & $74(4.7)$ & 0.51 & - & $0.07-3.84$ & 0.8 \\
Ave. birth weight $(\mathrm{kg})$ & $3.06 \pm 0.62$ & $3.24 \pm 0.54$ & - & 2.1 & - & $0.04^{*}$ \\
Stillbirths & 0 & $38(2.4)$ & - & - & - & - \\
Early neonatal death & $1(2.4)$ & $3(0.2)$ & 13.23 & - & $1.35-130.08$ & 0.20 \\
PMR/1000 births & $1(24.4)$ & $41(25.8)$ & 0.95 & - & $0.13-7.05$ & 0.96 \\
SCBUף Admission & $1(2.4)$ & $15(0.9)$ & 2.63 & - & $0.34-20.38$ & 0.87 \\
LBWł & $5(12.2)$ & $95(6.0)$ & 2.2 & - & $0.84-5.70$ & 0.20 \\
IUGR & $2(4.9)$ & $53(3.4)$ & 1.5 & - & $0.35-6.33$ & 0.92 \\
Macrosomia & $1(2.4)$ & $107(6.7)$ & 0.35 & - & $0.05-2.55$ & 0.44 \\
Congenital Anomaly & 0 & $1(0.1)$ & - & - & - & - \\
\hline
\end{tabular}

*Significant. All values in bracket are percentages, ๆ Special care baby unit, ł low birth weight 
The study group had no stillbirth unlike the control group that had 24 stillbirths per 1000 births. The Perinatal mortality was similar in both groups $(\mathrm{OR}=0.95, \mathrm{P}=1.0)$. The newborns of the study group about thrice required intensive care baby unit admission and were more likely to suffer early neonatal death. None of these was statistically significant. There was no hysterectomy or maternal death recorded among the subjects at the center within the period of this study.

\section{DISCUSSION}

The incidence of first child birth by teenage girls in this study was $1.1 \%$, this was lower than earlier reports of $1.7 \%-5.9 \%$ from this setting. ${ }^{13-14}$ The incidence reported by authors from other parts of Nigeria was $1.5-2.2 \%$ from the South West, ${ }^{9} \quad 1.67 \%-5.0 \%$ from South East, ${ }^{15-17} 6.2 \%$ in South-South, ${ }^{18} 11.8 \%$ from North West ${ }^{19}$ and from other parts of the world $4 \%-9 \%$ from Asia, ${ }^{12,} 202.9 \%$ in USA, ${ }^{21}$ and $0.2 \%$ in Europe. ${ }^{3}$ Most of these reports were child birth on combined nulliparous and parous teenagers unlike this study specifically on teenage first childbirth. This possibly led to the low incidence in this study. Reports from industrialized countries showed a declining teenage birth rate. ${ }^{21}$ Meanwhile, Nigerian national survey report of 2008 revealed a lower median age at first child birth in the Northern regions relative to the Southern regions of the country and rural dwelling as a risk factor unlike the urban setting ${ }^{4}$ as in this study. The low incidence in this study may equally be explained by the increasing safe sex practices among the youths in this setting especially increased use of condom for the prevention of human immunodeficiency virus (HIV) infection. Condom is attractive for contraception and prevention of the transmission of sexually transmitted infections (STIs and HIV. Again the city is currently home to many government, mission and private health facilities that offer various cares to women. Most of the unmarried and unsupported adolescents with unplanned and unwanted pregnancy end up with clandestine, albeit illegal abortion in the private health facilities for fear of school drop-out and other social reprisal for premarital childbirth in this setting.

The study group was significantly unmarried and of low educational and employment empowerment and this was an eloquent evidence of the weight of the involved social implications. This compared with other reports. ${ }^{13,17-18,22}$ Their educational, employment and marital disadvantaged status appeared to explain their increased risk of social and economic rejection commonplace in developing world with consequent adverse obstetric outcomes. This was unlike in the developed countries with better social system where both the incidence and the complications were declining. ${ }^{21,22}$ The poor access and utilization of prenatal services among the study group as evidenced in this data seemed suggestive of the lack of the necessary support for this group in poor resource settings. This contributes significantly to high maternal mortality in this group. ${ }^{24}$ Again they are mostly socially and psychologically withdrawn especially the unmarried with unplanned pregnancy. Inequality and inequity in children upbringing in most traditional settings that favor male child and tend to discriminate against the girl child in education and other empowerment opportunities prevalent in most developing countries ${ }^{1}$ is being addressed in the millennium development goal and other women and global efforts.

The study group appeared more prone to anemia in pregnancy. This was similar to previous findings. ${ }^{12,15,17}$, 20,23,25-27 This data seemed to corroborate anemia in pregnancy as a disorder of nutritional deficiency. The teenagers are still undergoing physical growth and development ${ }^{1}$ requiring a lot of nutrients and energy which combined with the high demands and stress from pregnancy increased the risk of nutritional deficiencies including the hematopoietic factors. This was amenable to quality prenatal care. The older mothers have more reserves and were physically better equipped for pregnancy therefore less prone to anemia as suggested from this data. Reported increased incidence of HIV infection among the teenage mothers ${ }^{17}$ could not be confirmed by this data.

Premature rupture of the fetal membranes appeared comparatively more among the study group corroborating another report. ${ }^{22}$ Similarly this group appeared relatively more prone to developing gestational hypertension as in other reports ${ }^{9,25,27}$ and in contrast to others. ${ }^{12,23}$ Young age and nulliparity are evidently associated with increased risk of pregnancy induced hypertension and pre-eclampsia. ${ }^{28}$

Perineal tear at vaginal delivery appeared more likely among the study group contrary to another report. ${ }^{12}$ This may possibly be due to their developing and rigid perineum. This necessitated their increased 
need for episiotomy corroborating other findings ${ }^{12}$, ${ }^{15,25}$. This data therefore suggested a careful perineal guard in labor to minimize perineal tear. Again this re-emphasized the need for Skilled attendance in labor for every parturient as one of the pillars for safe motherhood.

The teenagers generally underwent less interventional delivery corroborating previous reports. ${ }^{3,10}$ They had significantly less caesarean deliveries. This compared favorably with previous findings ${ }^{12,20,26}$ but at variant with other reports. ${ }^{1} 13-15,17-18,22-23$ Specifically there was reported reduced incidence of caesarean delivery among the teenagers from developed countries unlike those from developing countries. ${ }^{23}$

Generally, the neonates of the two arms appeared similar in adverse neonatal outcomes. Some of the adverse outcomes of the teenage pregnancy are related to the maternal gynecological age especially if it is less than 2 years when it indicates increased risk of preterm labor, LBW but not IUGR. ${ }^{1,29}$ These imply increased risk the younger or lower the chronological age and or lower the gynecological age of the pregnant adolescent. Nutritional deficiency and gestational hypertension are both associated with restricted fetal growth. There was $50 \%$ increased risk of IUGR among the study group. The Perinatal death rate was similar in the two groups corroborating previous reports ${ }^{9} 18$ and contrary to others. ${ }^{2,}{ }^{27}$ There

\section{REFERENCES}

1. WHO. Discussion Papers on Adolescence: Adolescent Pregnancy. Issues in Adolescent Health and Development. Geneva, World Health Organization, 2004.

2. Susan M. Pregnancy and childbirth are leading causes of death in teenage girls in developing countries. BMJ. 2004; 328 : 1152-2.

3. Treffers PE. Teenage pregnancy, a worldwide problem. Ned Tijdschr Geneeskd. 2003; 147: 2320-5.

4. National Population Commission (NPC) [Nigeria] and ICF International. Nigeria Demographic and Health Survey 2008. Abuja, Nigeria, and Rockville, Maryland, USA: NPC and ICF International. 2009.

5. Hanna B. Negotiating motherhood: the struggles of teenage mothers. J Adv Nurs. 2001; 34:456-64.

6. Roosa MW. Maternal age, social class and the obstetric performance of teenagers. J Youth and Adolescence. 1984; 13 (4): 365-74.

7. Odu B K, Ayodele C J. The Incidence of Teenage Pregnancy in Ekiti State, Nigeria. The Nigerian Journal of Guidance and Counseling. 2006; 11 (1): 25-33.

8. Odeniya O.M., Abiodun A.A., Oyejola B.A. Discrete Time Survival Analysis of Age at First Pregnancy among Nigerian were reports of increased preterm births $3,15,18,20,22-$ 23,25-27 but this study could not confirm this as in other reports ${ }^{10,12}$ probably because the teenagers in this study appeared older and in their first child birth unlike most of the other reports on teenage pregnancy in general. This risk appears indirectly related to the age of the teenage mother. ${ }^{1}$

This study drew its strength on its case control design. Its limitations are its being hospital based, lack of multicenter spread and randomization. Its findings therefore will not be generalizable but will contribute to the wealth of evidence on teenage childbirth. A larger study population sample size may influence some of the findings though this is not expected to have significant effect on a case control study. This was a retrospective data, a well designed prospective study will be more appropriate.

\section{CONCLUSIONS}

Teenage pregnancy and child birth is still high in our setting. Pregnant teenagers were comparatively more associated with social problems especially high rates of unmarried status, unemployment and low educational attainment. Nonetheless, they appeared generally comparable to the older counterparts in obstetric performance. We therefore recommend wholesome socioeconomic measures backed with quality obstetric care to contain the impact of teenage pregnancy. Promotion of contraceptive awareness and uptake is highly indicated.
Women. Research Journal of Applied Science. 2013; 8:215 -220 .

9. Adeyinka DA, Oladimeji O, Adekanbi TI, Adeyinka FE, Falope Y, Aimakhu C. Outcome of adolescent pregnancies in southwestern Nigeria: a case control study. J Matern Fetal Neonatal Med. 2010; 23(8): 785-9.

10. Mutihir JT, Maduka WE. Comparison of pregnancy Outcome between Teenage and older Primigravida in Jos University Teaching Hospital, Jos, North Central Nigeria. Ann Afr Med. 2006; 5:101-6.

11. Bahia N J, Armaghan D. Pregnancy outcome of parturients below 16 years of age. Saudi Med J. 2005; 26 (9): 14171419.

12. Sagili H, Pramya N, Prabhu K, Mascarenhas M, Reddi RP. Are teenage pregnancies at high risk? A comparison study in a developing country. Arch Gynecol Obstet.2012; 285 (3):5737.

13. Ebeigbe PN, Gharoro EP. Obstetric complications, intervention rates and materno-fetal outcome in teenage nullipara in Benin City, Nigeria. Trop Doct. 2007; 37: 79-83.

14. Gharoro EP, Igbafe AA. Maternal age at first birth and obstetric outcome. Niger J Clin Pract. 2002; 5:20-4. 
15. Ezegwui H U, Ikeako LC, Ogbuefi F. Obstetric outcome of teenage pregnancies at a tertiary hospital Enugu, Nigeria. Niger J Clin Pract. 2012; 15:147-50.

16. Sunday-Adeoye IM, Ogbonnaya LU, Osasuyi OO. Outcome of pregnancy in Adolescent mothers in Mile Four Hospital, Abakaliki, Ebonyi State. Orient J Med. 2006; 18:16-23.

17. Onoh RC, Ezeonu PO, Anozie BO, Esike CO, Obuna JA, Egbuji C, Agwu UM, Agboeze J, Chukwudi IP. Outcome of teenage pregnancy at a tertiary hospital in Abakaliki Southeast Nigeria. J Basic Clin Reprod Sci. 2014; 3:22-6.

18. Ibrahim IA, Owoeye G. Outcome of Teenage Pregnancy in the Niger Delta of Nigeria. Ethiop J Health Sci. 2012; 22(1): $45-50$.

19. Nwobodo EI, Adoke KU. Obstetric Outcome of teenage pregnancies at a tertiary care hospital in Sokoto, Nigeria. Trop J Obstet Gynaecol. 2005; 22:168-70.

20. Watcharaseranee N, Pinchantra P, Piyaman S. The incidence and complications of teenage pregnancy at Chonburi Hospital. J Med Assoc Thai. 2006; 89 (4):118-23.

21. Joyce A. M, Brady E. H, Michelle J.K. Osterman, Sally C. Curtin T.J. Mathews, Division of Vital Statistics: Births: Final Data for 2012, National Vital Statistics Reports. 2013; 62 (9).

22. Ogelle OM, Eke AC,Okafor CI, Mbamara SU, Obiechina NJ. Teenage pregnancies: a lingering obstetric problem in Nigeria. Niger J Med. 2011; 20(4): 414-20.
23. Scholl TO, Hediger ML, Belsky DH. Prenatal care and maternal health during adolescent pregnancy: A review and meta-analysis. Journal of Adolescent health.1994; 15(6):44456.

24. Ujah IA, Aisien OA, Mutihir JT, Vanderjagt DJ, Glew RH, Uguru VE. Maternal mortality among adolescent women in Jos, North-central, Nigeria. Trop J Obstet Gynaecol. 2005; 25:3-6.

25. Treffers PE, Olukoya AA, Ferguson BJ, Liljestrand J. Care for adolescent pregnancy and childbirth. Int J Gynaecol Obstet. 2001; 75:111-21.

26. Banpode S, Prapatsorn U. Maternal Age and Pregnancy Outcomes. Srinagarind Med J. 2007; 22(4):401-7.

27. Liu X, Zhang W. Effect of maternal age on pregnancy: a retrospective cohort study. Chin Med J. 2014; 127 (12): 2241 6.

28. Shennan A. Hypertensive disorders. In: D. Keith Edmonds (editor). Dewhurst's Textbook of Obstetrics and Gynecology. 7th ed.UK: Blackwell publishing; 2007.p 227-235.

29. Scholl TO, Hediger ML, Salmon RW, Belsky H, Ances G. Association between low gynaecologcial age and preterm birth. Paediatr Perinat Epidemiol. 1989; 3: 357-366. 